\title{
National Preferred Interpersonal Distance Curbs the Spread of COVID-19: A Cross-Country Analysis
}

\author{
Yunus Gokmen; Ufuk Turen (10; Haluk Erdem; İsmail Tokmak
}

\section{ABSTRACT}

Objectives: National interpersonal distance preference is considered a cultural characteristic. Interpersonal distance is critical for the spread dynamics of coronavirus disease 2019 (COVID-19). COVID-19's spread trend shows various characteristics in different countries. We believe that 1 of the factors influencing this variation could be national interpersonal distance preference.

Methods: We used regression analysis based on data of national interpersonal distance preferences (social, personal, and intimate) presented by Sorokowska et al. and COVID-19 rate of spread data for 40 different countries that were calculated using Our World in Data's data.

Results: National interpersonal distance preferences, with its 3 dimensions, significantly influence the rate of spread of COVID-19 in countries.

Conclusion: Understanding the relation between national interpersonal distance preference and spread of COVID-19 might be very useful information in decision-making processes of individuals, societies, and governments to develop culturally well-suited counter-pandemic policies, strategies, and procedures during the COVID-19 pandemic or any epidemic or pandemic threats in the future, instead of standard fit-to-all strategies.

Key Words: corona virus, COVID-19, interpersonal distance, pandemics, social distancing

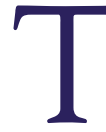

he disease caused by the novel coronavirus, which is believed to have started in Wuhan, China, in December 2019 and distinguished as a "pandemic" by the World Health Organization (WHO) in March 2020, is called novel coronavirus disease 2019 (COVID-19). Once the novel coronavirus propagated exponentially throughout the world and, in a couple of weeks, turned into one of the worst pandemics in history, the health systems of most nations were caught unprepared and suffered under the pressure of the exponential growth in the numbers of infected patients, especially the ones needing intensive care and respiratory support. ${ }^{1}$

Science is needed in this race run against time to halt the disease spread and its impact on the lives of tens of thousands of people without questioning social class or nationality. Although there are still many unknowns regarding COVID-19 and ways to fight it, we now know some of its transmission dynamics between humans and other indirect routes. Despite the general assumptions on viral spread by respiratory droplets and safe interpersonal distance of 2 meters, novel coronavirus can be transferred through fomites and aerosols, meaning safe interpersonal distance should be greater. $^{2,3}$ As a basic and classic strategy to contain the virus, most countries applied quarantine, isolation, or curfew policies to stop people from gathering and socializing, to mitigate the transmission of virus from one person to another.

Meanwhile, we noticed an interesting difference between nations in the rate of spread, despite sharing often the same social values and understanding of hygiene, presence of similar national health systems, and significant investment in science and technology. There might be many factors influencing the spread and impact of an infectious disease, such as the time at the first case enters the country, the robustness of national prevention and mitigation measures and policies applied, the strength of the health system, different testing strategies, active contact-tracing procedures, and other means and capabilities. ${ }^{4}$ However, nations' social habits, such as social contacts and mixing patterns, are also considered as credible factors in the process. ${ }^{5}$ It is also revealed that nations have different preferred interpersonal distancing habits (eg., Hall and Sorokowska et al.). ${ }^{6,7}$ Because the rapid spread of human-to-human transmitted COVID-19 is critically sensitive to the physical distance between individuals, ${ }^{8}$ we believe that the social habits of a nation relative to preferred interpersonal distance could be effective in the spreading process of COVID-19. Based on this idea, we explored the literature and could not find any research addressing this relationship. To fill the gap in the literature, we decided to explore the association 
between national interpersonal distance preferences and rate of COVID-19 spread in different societies.

Understanding the relation between preferred physical distance between individuals in a society and rate of spread of COVID-19 might be very useful information to be used in decision-making processes of individuals, societies, and governments to develop their counter-pandemic politics, strategies, and procedures during this COVID-19 pandemic or any epidemic or pandemic threads in the future. By doing so, wellsuited plans and strategies can be tailored based on the cultural preferences at all levels instead of standard manufactured fit-to-all strategies.

\section{BACKGROUND AND HYPOTHESES Interpersonal Distance}

Proxemic Theory's interpersonal distance concept, ${ }^{6}$ which is seen as an essential feature of bilateral relations between individuals $^{9}$ is considered an important form of nonverbal communication. ${ }^{10}$ Behaviors related to interpersonal distance are often related to the protection of certain proximities that people perceive as private. $^{11}$

The basic dimensions of these invisible borders differ according to cultural, social, personality, and environmental variables, and these borders ensure that the appropriate distance is maintained between individuals. ${ }^{12,13}$ This physical distance is seen as a tendency to approach or avoid social stimuli ${ }^{14}$ that often make people feel uncomfortable and threatened when that space is invaded. ${ }^{15}$ Interpersonal distance is sensitive not only to personal attitude toward another but also to gender, ${ }^{16}$ age, ${ }^{17}$ status and power, ${ }^{18}$ and culture. ${ }^{19}$

The concept of "social distance" is based on Simmel's ${ }^{20}$ theory of the stranger in the early 20th century. As a follower of Simmel, Bogardus ${ }^{21}$ proposes that individuals focus on their feelings toward each other, and defined social distance as a function of the degree of mutual sympathetic understanding, and establishes a scale of "social distance" beginning with the level of "someone to marry" and ending with "someone to exile from the country." Apart from this view, Hall's ${ }^{6}$ Proxemic Theory uses the term "interpersonal distance" and posits that it is a physical distance kept as personal breathing space, like an invisible bubble, that surrounds an individual representing an imaginary barrier to regulate intimacy with others by controlling the proximity of visual, tactile, auditory, and olfactory stimulation. This theory is based on the senses and mutual bodily stimulation effects between individuals, and focuses on the individual and his or her close approximations to others. The Proxemic Theory categorizes interpersonal distance in 4 intervals: (1) Intimate distance ( 0 in. -18 in.); all senses are active and there is love, family, or close friend relationships in between. (2) Personal distance $(1.5 \mathrm{ft}-4 \mathrm{ft}$ ); is the minimum comfortable distance between nontouching individuals, and this zone constitutes a small protective space.
(3) Social distance $(4 \mathrm{ft}-12 \mathrm{ft})$; is considered as the area where individuals do not care about each other and do not threaten each other. The distance of individuals at workplaces without disturbing each other can be given as an example. (4) Public distance ( $12 \mathrm{ft}$ and beyond); is the distance at which one can take either evasive or defensive action if physically threatened. Formal situations such as conference and speech can be given as examples. To prevent possible confusion in terms, the term "social distance," which is used by Bogardus, is also used by Hall to describe the third interval in his scale. It is believed that there is no intellectual influence between these 2 theoretical approaches, although they both explore almost the same aspect of social life. ${ }^{22}$

In addition, Hall ${ }^{6}$ categorizes cultures in 2 sets: contact and noncontact. Contact cultures are more inclined to touch each other, preferring shorted interpersonal distance while noncontact cultures show antipodal attitudes. He uses geographical division and suggests that contact culture dominates Southern European, Latin American, and Arabic and noncontact culture prevails in North American, Northern European, and Asian populations.

Little $^{23}$ compares perception of personal space of Swedish, Scottish, and American people with that of Greek and Italian people and finds that perception of personal space of Greek and Italian people is narrower. Watson ${ }^{24}$ in his research conducted on foreign students living in the United States, separates the students into 2 groups, similar to Hall, ${ }^{6}$ according to countries with high contact culture (Arabs, Latin Americans, South East Europeans) and those with low contact culture (North Americans, North Europeans, Pakistanis, and Asians) and investigates their perception of personal space. He reveals that personal spaces of students from countries with contact culture are narrower than personal spaces of those from countries without contact culture.

Remland et al. ${ }^{25}$ affirm that English, French, and Dutch people prefer greater personal space than Italian and Greek people. Beaulieu $^{26}$ sorts different cultures in terms of largest personal space size preference order: Anglo-Saxons come first, Asians second, and Caucasians third, and Mediterranean people and Latinos prefer the shortest distance. Tiechuan ${ }^{27}$ claims that interpersonal distance preference for Spanish or Arabic people is much closer than for British people, and interpersonal distance for people in Western culture is greater than Eastern culture. $\mathrm{Ke}$ and $\operatorname{Lian}^{28}$ report that interpersonal distance preferences differ between Chinese and American people. While Americans consider only spouses and children in their intimate space, Chinese people accept many more people in theirs. People waiting in crowded queues keep their personal spaces in American Society, whereas these spaces can be as close as physical contact in Chinese Society in similar circumstances. The impact of climate on interpersonal distance preferences is also examined. The individuals dwelling in hot climates are found to be friendlier and warmer than 
those living in cold climates (eg, Wei et al., Ven de Viliert, Ke and Lian, Sorokowska et al.)..$^{7,28-30}$

\section{Interpersonal Distance and Contagion}

From a medical perspective as a preventive measure, the interpersonal distance concept is frequently used as social distancing and being strongly advised to slow down the spread of contagion causing epidemics or pandemics (eg Ahmed et al., Fong et al., WHO, ECDC). ${ }^{31-34}$ Studies focusing on the spread dynamic of other epidemics and pandemics in history also suggest the spread rate of contagious virus can be significantly restrained by practice and policies that emphasize social distancing (eg, Caley et al.). ${ }^{35}$

During the COVID-19 pandemic, social distancing beyond the transmission range of virus is considered a key factor to stop virus spread from an infected individual to a healthy one and to flatten the curve of contagion spread to keep the total number of cases at any given time within the health systems' means and capabilities. ${ }^{36,37}$ The failure of society to practice social distance measures effectively often led to much more draconian and extremely costly governmental measures, such as quarantine, curfew, and lockdown to inhibit the speed of contagion spread. ${ }^{38,39}$ Some governments have delayed to take social distancing-related measures or gave inconsistent and confusing messages to people, making them perplexed, ${ }^{40}$ and some societies and groups simply resist the advised or instructed policies (eg, McMurtry and Zampano, Perrone). ${ }^{41,42}$

During our literature review, we find that there is one study exploring the association between interpersonal distance habits and the mortality caused by tuberculosis. This study used cross-country data and reported that greater national interpersonal distance preferences diminished the tuberculosis fatality rate. ${ }^{43}$ However, we cannot locate any study examining the relation between national interpersonal distance preference and spread rate of an infection during a pandemic.

We believe that this relation is critical for understand the social aspects of COVID-19 spread dynamics and useful to develop tailored preventive and mitigation plans for different societies and also notable to fill the gap in the literature. Hence, we theorize a greater COVID-19 spread rate in countries where people prefer shorter interpersonal distances compared with countries where they prefer greater distances, and we developed the hypotheses below:

$\mathrm{H}_{1}$ : Society's preferred interpersonal distance (total) influences COVID-19 spread rate.

$\mathrm{H}_{2}$ : Society's preferred social distance influences COVID-19 spread rate.

$\mathrm{H}_{3}$ : Society's preferred personal distance influences COVID-19 spread rate.

$\mathrm{H}_{4}$ : Society's preferred intimate distance influences COVID-19 spread rate.

\section{Methods and Data}

For national interpersonal distances, we used national interpersonal distances preference as function of 3 variables, namely social distance (SD), personal distance (PD), and intimate distance (ID) of countries around world, which was measured by Sorokowska et al. ${ }^{7}$ with a pioneering and comprehensive study, including 8943 participants from 42 different countries. For estimating interpersonal distance, participants were asked to fill a questionnaire including 3 graphical questions related to their preferred interpersonal distance. However, although the data set of national interpersonal distances data is not shown, we estimated sensitively using pixel/millimetric coordinate system approach (Jasc Paint Shop 8.0) based on the scaled graphic presented in the study. Although there are 4 intervals of interpersonal distance in Hall's model, ${ }^{6}$ we think the first 3 of them are the relevant approximations for viral transmission. Public distance, which is considered $12 \mathrm{ft}$ and beyond is excluded from our research scope. This interval is not measured by Sorokowska et al. ${ }^{7}$ as well.

To measure the increase in rate of spread of COVID-19, we used a simple exponential growth function (Equation 1), which is used for forecasting of the spread of an early phase of pandemic as stated by Anderson and May, ${ }^{44}$ Chowell et al., ${ }^{45}$ Wallinga and Lipsitch, ${ }^{46}$ and Viboud et al. ${ }^{47}$

$$
\mathrm{TC}_{i t}=\mathrm{TC}_{i t_{0}} \times e^{r_{i} t}
$$

$\mathrm{TC}_{i t}$ : Total COVID-19 cases of $\mathrm{i}^{\text {th }}$ country related to $\mathrm{t}^{\text {th }}$ day (April $7^{\text {th }}$ 2020),

$\mathrm{TC}_{i t 0}$ : Total COVID-19 cases of $\mathrm{i}^{\text {th }}$ country related to the date of reaching the $100^{\text {th }}$ cumulative case,

$r_{i}$ : The growth rate related to $\mathrm{i}^{\text {th }}$ country.

To compute the growth rate $(r)$ for each country, data on COVID-19 total cases (covering the period between the date of reaching the 100th cumulative case and April 7, 2020) are collected from Our World in Data (OWD) formal website, ${ }^{48}$ which sorts out daily COVID-19 data from the WHO situation reports. Hong Kong and Uganda are excluded from analysis, due to lack of COVID-19 total cases data. The data set is presented in Appendix A.

\section{Data Analysis}

We examined the impacts of national interpersonal distances (social, personal, and intimate distance) on the growth rate of total cases of COVID-19 (GRTC) totally and separately. To see the total effect, the average interpersonal distance of each nation is computed by using the geometric mean formula. Additionally, because the dependent and independent variables in the models have different measurement units, a simple logarithmic regression model is proposed, as stated in Equation 2-5. Regression models are powerful tools to estimate 
and/or predict the dependent variable's (population) mean by using 1 or more independent variables. ${ }^{49}$

$$
\begin{gathered}
\ln \mathrm{GRTC}_{i}=\beta_{0}+\beta_{1} \ln \mathrm{GMID}_{i}+\varepsilon_{i} \\
\ln \mathrm{GRTC}_{i}=\beta_{0}+\beta_{1} \ln \mathrm{SD}_{i}+\varepsilon_{i} \\
\ln \mathrm{GRTC}_{i}=\beta_{0}+\beta_{1} \ln \mathrm{PD}_{i}+\varepsilon_{i} \\
\ln \mathrm{GRTC}_{i}=\beta_{0}+\beta_{1} \ln \mathrm{ID}_{i}+\varepsilon_{i}
\end{gathered}
$$

GRTC $_{i}$ : The natural logarithm of Growth Rate of Total Cases of COVID-19 of $i^{\text {th }}$ country;

$\mathrm{GMID}_{i}$ : The natural logarithm of geometric mean of interpersonal distance values of $i^{\text {th }}$ country;

$\mathrm{SD}_{i}$ : The natural logarithm of Social Distance value of $i^{\text {th }}$ country;

$P D_{i}$ : The natural logarithm of Personal Distance value of $i^{\text {th }}$ country;

$I D_{i}$ : The natural logarithm of Intimate Distance value of $i^{\text {th }}$ country;

$\varepsilon_{i}$ : The error (residual) term in the regression model.

\section{RESULTS}

To test the hypotheses, simple regression analysis is conducted for each model. The summary of the regression models and coefficients is illustrated in Table 1 . We see that each national interpersonal distance value (GMID, SD, PD, and ID) has a significant and negative impact on GRTC. The results of regression models show that all coefficients in the models are significant at the $\alpha=0.05$ level, and the directions of the associations are in line with our hypotheses.

\section{DISCUSSION AND CONCLUSIONS}

In epidemics or pandemics, the spread rate of an infection is considered a major characteristic producing destruction in societies. Containing the spread is simply an effort to keep the number of severe cases needing intensive care within the capacity of health systems, gain time to increase health systems capacity, and develop drugs and vaccines. ${ }^{50}$ Today, distance kept among individuals to break the contagion chain is a classic and most-effective method for buying the time needed.

Our analyses show that there is a significant and negative (opposite) relation between national interpersonal distance preferences and COVID-19 spread rate. Based on Hall's Proxemic Theory, ${ }^{6}$ we separately used 3 sub-concepts, namely social, intimate, and personal distance preferences of nations to examine the impact of each on COVID-19 spread rate and determined that each increment of increase in distance for each variable leads to a decrease in COVID-19 spread rate.




Findings support our hypotheses and are in line with the only previously published study examining the relation between national interpersonal distance preference and tuberculosis fatality rate. ${ }^{43}$ In addition, the findings are supported by the medical prevention and mitigation measures and advice mentioned above (eg, ECDC, 2020), ${ }^{34}$ and the behavior of COVID-19 spread making Italy and Spain the epicenter in Europe, among many other nations. ${ }^{41}$ Thus, we can say that national interpersonal distance as 1 variable, and increases in each of its 3 dimensions significantly decrease the rate of spread of COVID-19 in a country. In other words, nations with greater interpersonal distance preference are less vulnerable to COVID-19 than the ones with shorter interpersonal distance preference.

We think that this study is important because it supports the social dimension of pandemics. Interpersonal distance preferences of nations and their social and cultural properties are sustained but slowly change over time. Being cognizant of these cultural behavioral patterns' impact on medical phenomena is critical. Apart from technical and medical precautions and measures, this social aspect having an impact on viral transmission dynamics can be key for decision-makers, authorities, and ordinary people. If governments use this information during their decision-making processes related to pandemics, such as COVID-19 and upcoming epidemic or pandemic threats, they can develop more realistic, tailored, and effective plans reflecting the habits and preferences of their citizens. In this regard, we can suggest that, in societies with shorter interpersonal distance preferences, governments should take much more draconian and early preventive measures and remind people about their habits and invite them to practice greater interpersonal distance. If there is no information about the facts, correction efforts are often inappropriate and useless. Governments unaware of the interpersonal distance preference of their pertinent society often use standard measures widely accepted in the international community but not well tailored for their particular community.

We also think our findings are valuable because they promote the idea of a social or interpersonal distancing strategy in fighting COVID-19 through providing cross-country evidence supporting its effective functionality.

This study is the first study examining the relation between national interpersonal distance preferences and the spread rate of an infectious disease. In this respect, it is valuable because it fills an important gap in the literature. Furthermore, we believe that the relations between the social behavior of people and pandemic-related matters should be explored further to understand the variance among different societies. Only by understanding social science can we appreciate the contribution of human behavior and culture in this phenomenon and learn lessons for all.
Our study has some limitations. We used secondary data in our analyses. The data on rate of spread is derived from OWD, ${ }^{48}$ and national interpersonal distance preference data are from Sorokowska et al. ${ }^{7}$ So, we assume that the data presented by these sources are true and accurate. COVID-19 rate of spread is based on the data collected during a limited time interval, by April 7, 2020. Because the pandemic is still spreading globally, COVID-19 rates can vary over time. Our data source for national interpersonal distance preference, Sorokowska et al., ${ }^{7}$ addresses 42 countries; therefore, our analyses are limited to those societies. These limitations should be considered before any generalizations.

Pandemics are also likely to impact interpersonal distance preference (eg, Faulkner et al.), ${ }^{51}$ and this relation is also valuable to understand the impact of the COVID-19 pandemic on societies. Efforts to measure national interpersonal distance preferences after the COVID-19 pandemic could be very useful to see the variation between before and after, if any, and recalibrate the international database for the concept.

\section{About the Authors}

Turkish Military Academy, Ankara, Turkey (Drs Gokmen, Turen, Erdem) and Baskent University, Ankara, Turkey (Dr Tokmak)

Correspondence and reprint requests to Ufuk Turen, Kara Harp Okulu, Ankara, Turkey 06654 (e-mail: uturen2011@gmail.com).

\section{Conflict of Interest Statement}

The authors declare that they have no conflicts of interest at this time.

\section{REFERENCES}

1. Horton R. Offline: COVID-19 and the NHS-"a national scandal". Lancet. 2020;395(10229):1022. doi: 10.1016/S0140-6736(20)30727-3

2. Bourouiba L. Turbulent gas clouds and respiratory pathogen emissions: potential implications for reducing transmission of COVID-19. JAMA. 2020. doi: $10.1001 /$ jama.2020.4756

3. Galbadage T, Peterson BM, Gunasekera RS. Faculty articles \& research. Does COVID-19 spread through droplets alone? 2020. https://digitalcommons.biola.edu/faculty-articles/408. Accessed August 21, 2020.

4. Michaels JA, Stevenson MD. Explaining national differences in the mortality of Covid-19: Individual patient simulation model to investigate the effects of testing policy and other factors on apparent mortality. medRxiv. 2020. https://doi.org/10.1101/2020.04.02.20050633

5. Mossong J, Hens N, Jit M, et al. Social contacts and mixing patterns relevant to the spread of infectious diseases. PLoS Med. 2020;5(3):e74. doi: 10.1371/journal.pmed.0050074

6. Hall ET. The Hidden Dimension. New York: Doubleday; 1966.

7. Sorokowska A, Sorokowski P, Hilpert P, et al. Preferred interpersonal distances: a global comparison. J Cross Cult Psychol. 2017;48:577-592. https://doi.org/10.1177/0022022117698039

8. Tomasi D. Coronavirus Disease (COVID-19). A Socioepidemiological Analysis. Burlington, VT: Vermont Academy of Arts and Sciences LV:1-7. 2020. 
9. Dickson JP, MacLachlan DL. Social distance and shopping behavior. JAMS. 1990;18:153-161. https://doi.org/10.1007/BF02726431

10. Iachini T, Coello Y, Frassinetti F, et al. Peripersonal and interpersonal space in virtual and real environments: effects of gender and age. J Environ Psychol. 2016;45:154-164. https://doi.org/10.1016/j.jenvp.2016. 01.004

11. Danesi M. Proxemics. In: Brown K, ed. Encyclopedia of Language and Linguistics. 2nd ed. Boston: Elsevier; 2006:241-243.

12. Riem MME, Kunst LE, Steenbakkers FDF, et al. Oxytocin reduces interpersonal distance: Examining moderating effects of childrearing experiences and interpersonal context in virtual reality. Psychoneuroendocrinology. 2019;108:102-109. doi: 10.1016/j.psyneuen.2019.06.012

13. Karakayali N. Social distance and affective orientations. Sociol Forum (Randolph N J). 2009;24:538-562. doi: 10.1111/j.1573-7861.2009.01119

14. Cohen D, Shamay-Tsoory S. Oxytocin regulates social approach. Social Neuroscience 2018;13:680-687. doi: 10.1080/17470919.2017. 1418428

15. Kim Y, Kwak SS, Kim M. Am I acceptable to you? Effect of a robot's verbal language forms on people's social distance from robots. Comput Human Behav. 2013;29:1091-1101. doi: 10.1016/j.chb.2012.10.001

16. Uzzell D, Horne N. The influence of biological sex, sexuality and gender role on interpersonal distance. $\mathrm{Br} J$ Soc Psychol. 2006;45:579-597. doi: 10. $1348 / 014466605 \times 58384$

17. Winogrond IR. A comparison of interpersonal distancing behavior in young and elderly adults. Int J Aging Hum Dev. 1981;13:53-60. doi: 10. 2190/tt33-D5JK-N23N-6YMT

18. Peker M, Booth RW, Eke A. Relationships among self-construal, gender, social dominance orientation, and interpersonal distance. J Appl Soc Psychol. 2018;48:494-505. doi: 10.1111/jasp.12529

19. Forston RF, Larson CU. The dynamics of space: an experimental study in proxemic behavior among Latin Americans and North Americans. J Commun. 2006;18:109-116. doi: 10.1111/j.1460-2466.1968.tb00061

20. Simmel G. The stranger. In: Wolff K ed. The Sociology of Georg Simmel. London, New York: The Free Press; 1950:402-408.

21. Bogardus ES. Social Distance. Los Angeles: University of Southern California Press; 1959:7.

22. Rogers EM, Hart WB, Miike Y. Edward T. Hall and the history of intercultural communication: the United States and Japan. Keio Commun Rev. 2002;24:3-26

23. Little KB. Cultural variations in social schemata. J Pers Soc Psychol. 1968;10:1-7. doi: 10.1037/h0026381

24. Watson OM. Proxemic Behavior: A Cross-cultural Study. Paris: Mouton; 1970:52-55

25. Remland MS, Jones TS, Brinkman H. Interpersonal distance, body orientation, and touch: effects of culture, gender, and age. J Soc Psychol. 1995;135:281-297. doi: 10.1080/00224545.1995.9713958

26. Beaulieu C. Intercultural study of personal space: a case study. J Appl Soc Psychol. 2004;34:794-805. doi: 10.1111/j.1559-1816.2004.tb02571.x

27. Tiechuan M. A study on nonverbal communication in cross-culture. Asian J Humanit Soc Sci. 2016;4:1-6.

28. Ke Z, Lian Y. An analysis on proxemics phenomenon between China and America. J Lit Art Stud. 2017;7:1320-1325. doi: 10.17265/2159-5836/ 2017.10.012

29. Wei W, Lu JG, Galinsky AD, et al. Regional ambient temperature is associated with human personality. Nat Hum Behav. 2017;1:890-895. doi: $10.1038 / s 41562-017-0240-0$

30. Van de Vliert E. Climatic imprints on personality. Nat Hum Behav. 2017;1:864-865. doi: 10.1038/s41562-017-0246-7

31. Ahmed F, Zviedrite N, Uzicanin A. Effectiveness of workplace social distancing measures in reducing influenza transmission: a systematic review. BMC Public Health. 2018;18:1-13. doi: 10.1186/s12889-018-5446-1

32. Fong MW, Gao H, Wong JY, et al. Nonpharmaceutical measures for pandemic influenza in nonhealthcare settings-social distancing measures. Emerg Infect Dis. 2020;26:976-984. doi: 10.3201/eid2605.190995
33. WHO. Global influenza programme-non-pharmaceutical public health measures for mitigating the risk and impact of epidemic and pandemic influenza. 2019. https://www.who.int/influenza/publications/public_health_ measures/publication/en/. Accessed April 12, 2020.

34. ECDC. Considerations relating to social distancing measures in response to COVID-19- technical report. https://www.ecdc.europa.eu/sites/default/ files/documents/covid-19-social-distancing-measuresg-guide-secondupdate.pdf. Accessed April 12, 2020.

35. Caley P, Philips DJ, McCracken K. Quantifying social distancing arising from pandemic influenza. J R Soc Interface. 2007;5:631-639. doi: 10.1098/ rsif.2007.1197

36. Kupferschmidt K, Cohen J. China's aggressive measures have slowed the coronavirus. They may not work in other countries. 2020. https://www. sciencemag.org/news/2020/03/china-s-aggressive-measures-have-slowedcoronavirus-they-may-not-work-other-countries\#. Accessed April 14, 2020.

37. France 24. France's coronavirus death toll tops 1,000 , lockdown likely to be extended. 2020. https://www.france24.com/en/20200324-france-s-scientificcouncil-says-coronavirus-lockdown-should-last-at-least-six-weeks. Accessed April 16, 2020.

38. Woodward A, Perper R. Wuhan, China, and at least 15 other cities have been quarantined as China attempts to halt the spread of the coronavirus. That's about 50 million people on lockdown. Business Insider. 2020. https://www.businessinsider.com/wuhan-coronavirus-officials-quarantineentire-city-2020-1. Accessed April 14, 2020.

39. NBC News. Coronavirus: Europe tightens lockdowns while others ignore social distancing advice. 2020. https://www.nbcnews.com/news/world/ coronavirus-europe-tightens-lockdowns-while-others-ignore-social distancing-advice-n1166376. Accessed April 16, 2020.

40. Horowitz J, Bubola E, Povoledo E. Italy, pandemic's new epicenter, has lessons for the world. New York Times. https://www.nytimes.com/2020/ 03/21/world/europe/italy-coronavirus-center-lessons.html. Published March 21, 2020. Accessed April 17, 2020.

41. McMurtry A, Zampano G. COVID-19: what went wrong in Italy and Spain? 2020. https://www.aa.com.tr/en/europe/covid-19-what-went-wrongin-italy-and-spain/1797461. Accessed April 17, 2020.

42. Perrone A. How Italy became the ground zero of Europe's coronavirus crisis. 2020. https://www.wired.co.uk/article/coronavirus-italy. Accessed April 17, 2020.

43. Gerace TA, Vorp R. Interpersonal distance: a factor in infectious disease morbidity and mortality? Med Hypotheses. 1985;17:271-275. doi: 10.1016/ 0306-9877(85)90133-1

44. Anderson RM, May RM. Infectious Diseases of Humans. Oxford: Oxford University Press; 1991.

45. Chowell G, Nishiura H, Bettencourt LM. Comparative estimation of the reproduction number for pandemic influenza from daily case notification data. J R Soc Interface. 2007;4:155-166. doi: 10.1098/rsif.2006.0161

46. Wallinga J, Lipsitch M. How generation intervals shape the relationship between growth rates and reproductive numbers. Proc Biol Sci. 2007;274: 599-604. doi: 10.1098/rspb.2006.3754

47. Viboud C, Simonsen L, Chowell G. A generalized-growth model to characterize the early ascending phase of infectious disease outbreaks. Epidemics. 2016;15:27-37. doi: 10.1016/j.epidem.2016.01.002

48. OWD (Our World in Data). Coronavirus source data. 2020. https://ourworldindata.org/coronavirus-source-data. Accessed April 7, 2020.

49. Gujarati DN. Basic Econometrics. New York: McGraw-Hill; 2004.

50. Faherty LJ, Schwartz HL, Ahmed F, et al. School and preparedness offcials' perspectives on social distancing practices to reduce influenza transmission during a pandemic: Considerations to guide future work. Prev Med Rep. 2019;14:1-6. doi: 10.1016/j.pmedr.2019.100871

51. Faulkner J, Schaller M, Park JH, et al. Evolved disease-avoidance mechanisms and contemporary xenophobic attitudes. Group Process Intergroup Relat. 2004;7:333-353. doi: 10.1177/1368430204046142 


\section{APPENDIX A}

\section{Data Set of Dependent and Independent Variables ${ }^{a}$}

\begin{tabular}{|c|c|c|c|c|c|c|}
\hline \multirow[b]{2}{*}{ ID } & \multirow[b]{2}{*}{ Country } & \multirow{2}{*}{$\begin{array}{l}\text { Dependent Variable } \\
\text { Growth Rate of Total } \\
\text { Cases (GRTC) }\end{array}$} & \multicolumn{4}{|c|}{ Independent Variables $(\mathrm{cm})^{\mathrm{b}}$} \\
\hline & & & $\begin{array}{c}\text { Geometric Mean of } \\
\text { Interpersonal } \\
\text { Distance (GMID) }\end{array}$ & $\begin{array}{c}\text { Social } \\
\text { Distance (SD) }\end{array}$ & $\begin{array}{c}\text { Personal } \\
\text { Distance (PD) }\end{array}$ & $\begin{array}{c}\text { Intimate } \\
\text { Distance (ID) }\end{array}$ \\
\hline 1 & Argentina & 0.1338 & 57.45 & 77.33 & 59.33 & 41.33 \\
\hline 2 & Austria & 0.1597 & 67.47 & 88.00 & 68.00 & 51.33 \\
\hline 3 & Brazil & 0.1917 & 75.38 & 101.33 & 77.33 & 54.67 \\
\hline 4 & Bulgaria & 0.0871 & 62.25 & 82.67 & 65.33 & 44.67 \\
\hline 5 & Canada & 0.1884 & 85.80 & 102.67 & 84.67 & 72.67 \\
\hline 6 & China & 0.0743 & 82.14 & 114.67 & 83.33 & 58.00 \\
\hline 7 & Colombia & 0.1370 & 84.37 & 116.00 & 85.33 & 60.67 \\
\hline 8 & Croatia & 0.1297 & 90.36 & 108.67 & 89.33 & 76.00 \\
\hline 9 & Czech Republic & 0.1434 & 79.83 & 110.00 & 80.67 & 57.33 \\
\hline 10 & Estonia & 0.0944 & 91.23 & 117.33 & 93.33 & 69.33 \\
\hline 11 & Germany & 0.1788 & 65.94 & 96.00 & 70.00 & 42.67 \\
\hline 12 & Ghana & 0.0647 & 78.51 & 106.67 & 82.00 & 55.33 \\
\hline 13 & Greece & 0.0992 & 66.77 & 92.00 & 69.33 & 46.67 \\
\hline 14 & Hungary & 0.1151 & 104.69 & 129.33 & 107.33 & 82.67 \\
\hline 15 & India & 0.1621 & 82.39 & 110.00 & 86.67 & 58.67 \\
\hline 16 & Indonesia & 0.1330 & 84.96 & 110.00 & 85.33 & 65.33 \\
\hline 17 & Iran & 0.1482 & 82.12 & 112.00 & 83.33 & 59.33 \\
\hline 18 & Italy & 0.1571 & 64.70 & 93.33 & 68.00 & 42.67 \\
\hline 19 & Kazakhstan & 0.1433 & 67.69 & 94.67 & 67.33 & 48.67 \\
\hline 20 & Kenya & 0.0724 & 82.18 & 110.00 & 88.00 & 57.33 \\
\hline 21 & Malaysia & 0.1200 & 73.28 & 110.00 & 76.67 & 46.67 \\
\hline 22 & Mexico & 0.1514 & 81.26 & 99.33 & 82.67 & 65.33 \\
\hline 23 & Nigeria & 0.0746 & 80.36 & 102.67 & 80.67 & 62.67 \\
\hline 24 & Norway & 0.1228 & 65.39 & 104.00 & 72.00 & 37.33 \\
\hline 25 & Pakistan & 0.1377 & 84.43 & 118.00 & 90.00 & 56.67 \\
\hline 26 & Peru & 0.1470 & 61.63 & 80.67 & 64.00 & 45.33 \\
\hline 27 & Poland & 0.1562 & 68.25 & 96.67 & 66.67 & 49.33 \\
\hline 28 & Portugal & 0.1861 & 73.63 & 110.00 & 76.67 & 47.33 \\
\hline 29 & Romania & 0.1492 & 84.09 & 134.67 & 92.00 & 48.00 \\
\hline 30 & Russia & 0.1914 & 67.57 & 89.33 & 74.00 & 46.67 \\
\hline 31 & Saudi Arabia & 0.1332 & 107.76 & 125.33 & 104.00 & 96.00 \\
\hline 32 & Serbia & 0.1505 & 65.32 & 92.67 & 67.33 & 44.67 \\
\hline 33 & Slovakia & 0.0804 & 63.72 & 88.67 & 67.33 & 43.33 \\
\hline 34 & South Korea & 0.0894 & 83.30 & 105.33 & 84.00 & 65.33 \\
\hline 35 & Spain & 0.1966 & 72.55 & 90.00 & 74.00 & 57.33 \\
\hline 36 & Switzerland & 0.1449 & 91.03 & 110.00 & 92.67 & 74.00 \\
\hline 37 & The United Kingdom & 0.1850 & 76.86 & 99.33 & 80.67 & 56.67 \\
\hline 38 & The United States & 0.2273 & 68.30 & 95.33 & 68.67 & 48.67 \\
\hline 39 & Turkey & 0.2532 & 87.37 & 122.67 & 92.67 & 58.67 \\
\hline 40 & Ukraine & 0.1890 & 61.14 & 86.00 & 65.33 & 40.67 \\
\hline
\end{tabular}

${ }^{\text {a }}$ Hong Kong and Uganda are excluded from analysis, due to lack of COVID-19 total cases data. The decimal parts of independent variables are rounded to 2 digits.

${ }^{\mathrm{b}}$ In order to ensure normality and homoscedasticity assumptions, transformation methods (logarithm and simple smoothing) are conducted before regression analysis. 